\title{
CYSTIC FIBROSIS AND COMMON VARIABLE IMMUNODEFICIENCY
}

KBC

Duška Tješić-Drinković ${ }^{1,2}$, Jadranka. Kelečić ${ }^{1}$, Andrea Vukić-Dugac ${ }^{1,2}$, Dorian T-Drinković1,2

Cystic Fibrosis Center - University Hospital Centre Zagreb and Zagreb School of Medicine

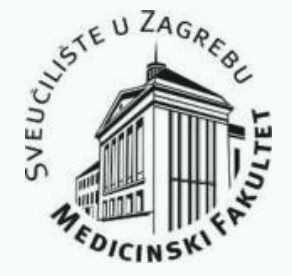

\section{Background}

Cystic fibrosis (CF) is the most common hereditary disease that shortens life span in Caucasians with great phenotype variations between and within affected individuals. Production of thick, viscous secretions affecting all organs with mucus-secretory glands, e.g. airways, pancreas, gut, biliary tract, reproductive tract and sweat glands are hallmarks of the disease. It is known that certain Immunological disturbances play a role in the expression of cystic fibrosis (CF). Common variable immunodeficiency (CVID) is one of the most common immunological disorders characterized by defective humoral immunity and consequently recurrent infections of different sites.

\section{Objectives and methods}

We looked for the possible presence of CVID among patients with $\mathrm{CF}$ and the course of $\mathrm{CF}$ in such individuals. Immunoglobulin levels were measured during the yearly check-up in 59 patients followed at the CF center attached to the University Hospital Centre in Zagreb during yr 2016. One patient was identified with low lgG level. Further investigations to prove immunodeficiency was carried out, and the documentation regarding CF was evaluated.

\section{Case report}

The patient is a 13 y old boy, homozygous for F508del. He fulfills the criteria for immunodeficiency. He has low isohemaglutinine titre: anti-B IgM 64 (score 49), anti-B IgG2 (score 6), normal immunophenotypisation of peripheral lymphocytes, no response to immunization against hepatitis B. The IgG concentration remained low in consecutive remeasurements from 2016. y. until now (4.6-6.0 g/L). IgA and IgM levels are within the normal rage (Figure 1).

The patient has neither protein loss nor malnutrition except vitamin D insufficiency. His BMI on the 48th percentile.

$\mathrm{He}$ is intermittently colonized with Pseudomonas aeruginosa with negative or low number of PMN in sputum. MSCT documented chronical structural changes (Figure 2). diffuse deformation of bronchi with ecstasies basally bilaterally. His pulmonary function is normal (FEV1 is $106 \%$ p.v., MEF 50 99.9\% p.v.).
Figure 1. Immunoglobulin variations 2016. - 2018.

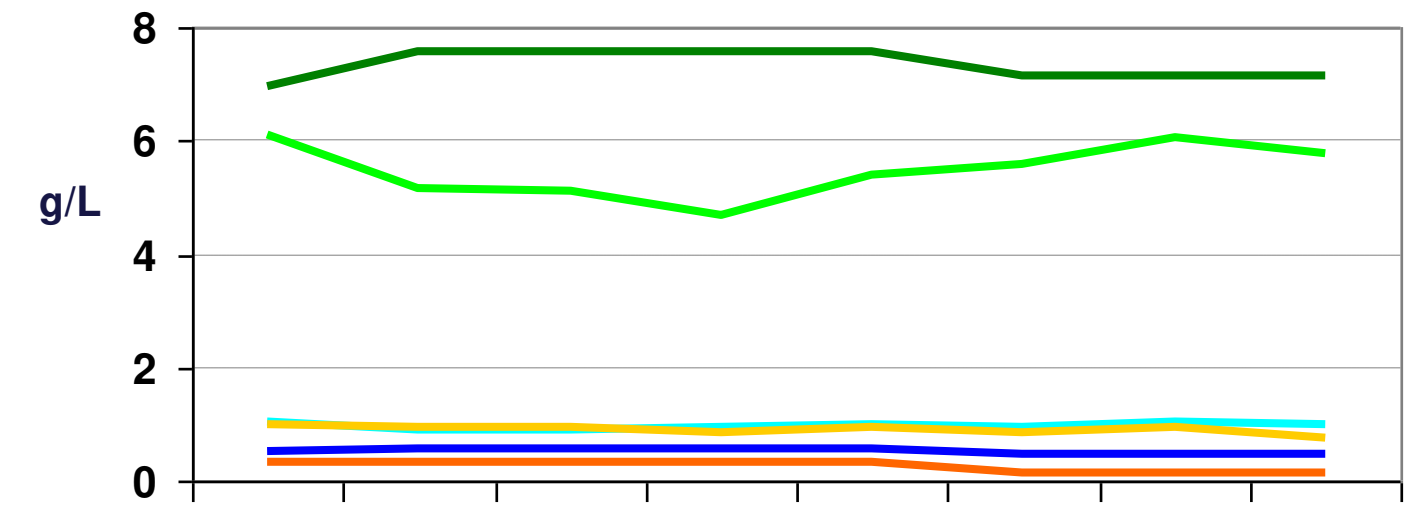

\begin{tabular}{|l|c|c|c|c|c|c|c|c|}
\hline - ref IgG & 6,98 & 7,59 & 7,59 & 7,59 & 7,59 & 7,16 & 7,16 & 7,16 \\
\hline - IgG & 6,13 & 5,18 & 5,12 & 4,68 & 5,39 & 5,6 & 6,06 & 5,76 \\
\hline - ref IgA & 0,53 & 0,58 & 0,58 & 0,58 & 0,58 & 0,47 & 0,47 & 0,47 \\
\hline - IgA & 1,03 & 0,91 & 0,91 & 0,96 & 1 & 0,95 & 1,03 & 0,98 \\
\hline - ref IgM & 0,31 & 0,35 & 0,35 & 0,35 & 0,35 & 0,15 & 0,15 & 0,15 \\
\hline$-\operatorname{IgM}$ & 0,99 & 0,94 & 0,94 & 0,87 & 0,93 & 0,83 & 0,95 & 0,74 \\
\hline
\end{tabular}

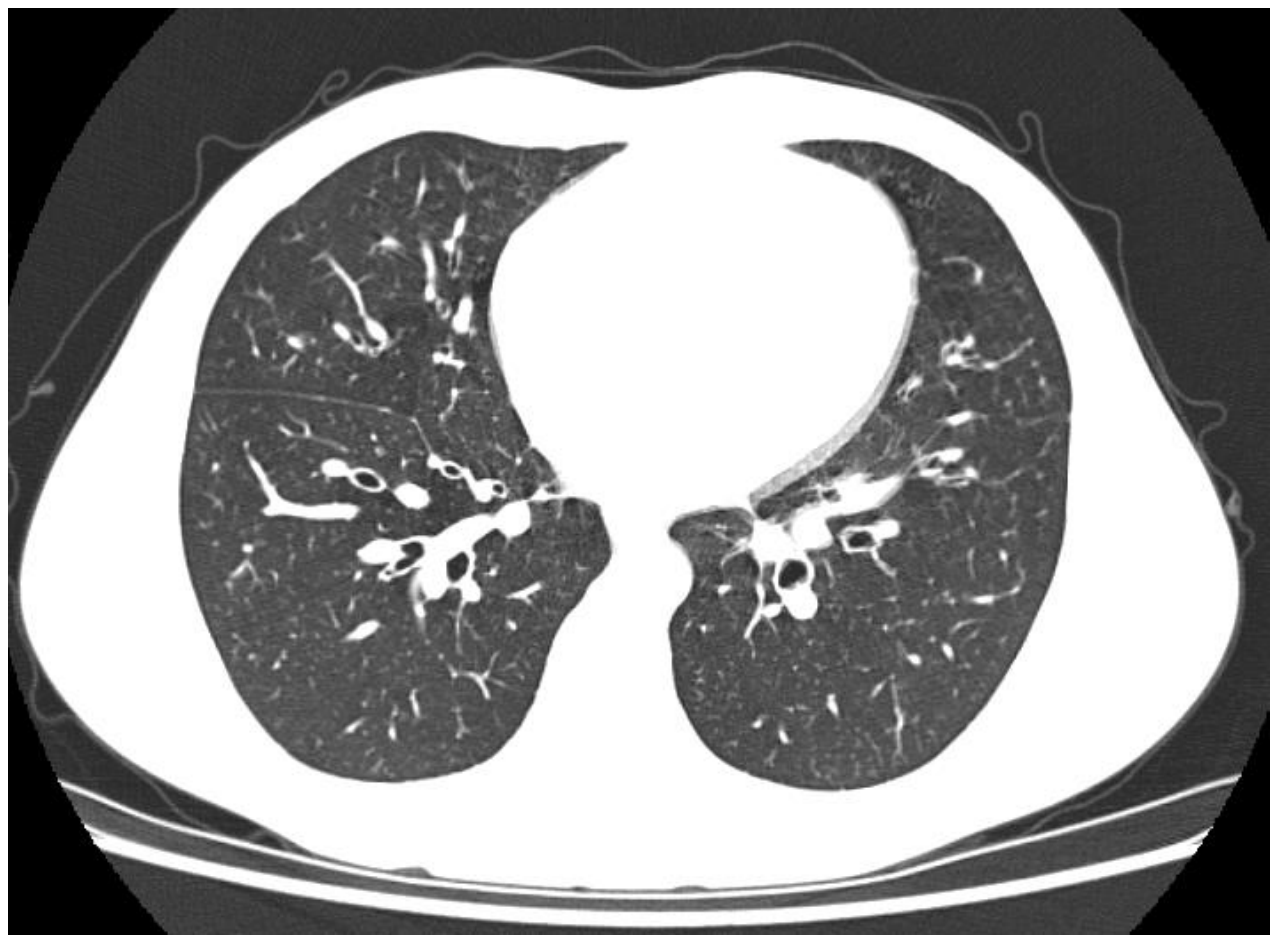

Figure 2. MSCT scan showing diffuse deformation of bronchi with ecstasies basally bilaterally

\section{Conclusion}

The coexistence of CF and CVID has been rarely described and its significance in unknown. One would expect a more severe course of $\mathrm{CF}$ due to immunodeficiency. In the case of this patient who does not have a severe CF phenotype, it does not seem likely that the coexistence of low IgG levels aggravates the expression CF lung disease. However, it has been reported previously that substitution immunotherapy leads to better pulmonary status in cases of the coexistence of CF and CVID.

This and similar observations can be the starting point for designing studies in order to better understand the intriguing relationship of CVID and CF. 